\title{
Frailty assessment in older adults with chronic obstructive respiratory diseases
}

This article was published in the following Dove Press journal:

Clinical Interventions in Aging

\section{Chunyan Guan \\ Huiyan Niu}

Department of Geriatrics, Sheng Jing Hospital, China Medical University, Shenyang, People's Republic of China
Correspondence: Huiyan Niu Department of Geriatrics, Sheng Jing Hospital, China Medical University, 36 Sanhao Street, Shenyang I 10004 , Liaoning Province, People's Republic of China

Tel +86 I 8940255686

Email niuhy@sj-hospital.org

\begin{abstract}
The number of patients with chronic obstructive pulmonary disease (COPD) has been rising with continued exposure to environmental risk factors and aging of populations around the world. Frailty is a geriatric syndrome with a decline in physiological reserve and often coexists with chronic diseases such as COPD. Frailty is an independent risk factor for the development and progression of COPD, and COPD can lead to frailty; treating one might improve the other. Thus, there is an increasing interest in the assessment of frailty in patients with COPD. Furthermore, early identification and assessment of frailty in patients with COPD may affect the choice of intervention and improve its effectiveness. Based on the current literature, the intent of this review was to summarize and discuss frailty assessment tools used for COPD patients and the relevant clinical practices for predicting outcomes. We ascertain that using suitable frailty assessment tools could facilitate physicians to screen and stratify physically frail patients with COPD. Screening appropriately targeted population can achieve better intervention outcomes and pulmonary rehabilitation among frail COPD patients.
\end{abstract}

Keywords: frailty, COPD, elderly, assessment, intervention

\section{Introduction}

As the world's population ages, frailty is becoming more and more important in health and medical care. Frailty can be regarded as a common sequela of aging; however, it is different from aging and disability as up to $75 \%$ of patients $>85$ years of age are not frail. ${ }^{1}$ Frailty is a geriatric syndrome that has been defined as a state of increased vulnerability from age-associated decline in reserve and function, resulting in reduced ability to cope with daily or acute stressors. ${ }^{2,3}$ Once stressors strike, frail older adults are more prone to disastrous health outcomes, even disability and death. ${ }^{4-7}$ Frailty has been shown to be highly correlated with the quality of life, hospital admissions, and mortality, ${ }^{8-11}$ as well as untoward consequences of other geriatric syndromes, such as falls, delirium, depression, cognitive impairment, and incontinence. ${ }^{12}$ It should be noted that frailty, in our belief, definitely calls for a practical and a more holistic viewpoint in the care of elderly patients. ${ }^{13}$ However, the symptoms of frailty will go unnoticed by physicians in primary care and clinics, unless frailty is actively identified. The authors are happy to see that an international consensus group has suggested that all persons $>70$ years of age should be screened for frailty. ${ }^{14}$

Frailty often coexists with chronic diseases. Recent studies have suggested a higher prevalence of frailty in people with chronic conditions. ${ }^{15,16}$ Despite the fact that more than half of the older people with chronic diseases such as heart failure ${ }^{17}$ and chronic obstructive pulmonary disease (COPD) might be frail, ${ }^{6}$ most physicians often focus on specific diseases, such as diabetes, heart failure, and COPD, instead of the early diagnosis 
and intervention of frailty, which might lead to the occurrence of unexpected adverse outcomes in older adults. Once frailty develops, a new physiological stressor (eg, acute exacerbation of COPD [AE-COPD] or critical illness) can overwhelm the already diminished physiologic reserve, resulting in disability, severe morbidity, or even death. ${ }^{18}$ Therefore, the American Geriatrics Society (AGS), the National Institute on Aging (NIA), and the Alliance for Academic Internal Medicine held a joint conference in 2015 with the purpose to advance the field of frailty research among relevant medical specialties. ${ }^{19}$

COPD is a common, preventable, treatable disease that is characterized by persistent respiratory symptoms and airflow limitations. COPD is usually progressive and associated with an enhanced chronic inflammatory response in the airways and the lung to noxious particles or gases. ${ }^{20} \mathrm{COPD}$ is projected to become the third leading cause of death by 2020. More than 3 million people died of COPD in 2012, accounting for $6 \%$ of all deaths globally. ${ }^{21}$ The COPD burden is projected to increase in the ensuing decades because of continuing exposure to COPD risk factors and the aging of the population. ${ }^{22}$ In the elderly, the diagnosis of COPD is often delayed due to atypical symptoms; the frequency of acute exacerbations is higher than that in the younger people, and respiratory failure is more likely to occur among the elderly.

To date, frailty has been used to assess many chronic diseases, such as cardiovascular diseases, chronic kidney disease, and obesity. ${ }^{23-25}$ Increasing attention is being given to frailty assessment in patients with chronic lung diseases. ${ }^{26}$ Indeed, several recent studies have shown a significant increase in the incidence of frailty in chronic lung disease. ${ }^{27,28}$ The prognostic utility of frailty in patients with chronic respiratory diseases for mortality and hospitalization has been validated, ${ }^{29-31}$ and physical frailty has been shown to be amenable to treatment with pulmonary rehabilitation. ${ }^{32}$ However, frailty assessment in older adults with COPD is still controversial. In this review, we summarized assessment tools for frailty in patients with COPD, briefly presented the underlying pathological pathways and potential biomarkers for frailty and COPD, and discussed the strategies for prevention and intervention in frail older adults with COPD.

\section{Prevalence of frailty in patients with COPD}

Depending on the assessment methods and heterogeneity of the population, the prevalence of frailty varies greatly. ${ }^{33,34}$ The general trend of frailty prevalence increases with age, and the prevalence in women is higher than that in men.
Frailty is estimated to affect $10.7 \%$ of community-dwelling adults $>65$ years of age, $15.7 \%$ of adults $80-84$ years of age, and $26.1 \%$ of adults $>85$ years of age.$^{35}$ In frail females, the probability of falling is threefold greater than those who are not frail. ${ }^{36}$

The prevalence of frailty in patients with COPD has been reported to range from $6.6 \%$ to $75.5 \%$, depending on the populations studied the frailty screening tools used; ${ }^{6,28,29,32}$ frailty has been shown to correlate with the severity of COPD. ${ }^{4,29}$ A recent meta-analysis ${ }^{37}$ showed that patients with COPD have a twofold greater risk for frailty than patients without COPD. Specifically, the pooled prevalence of prefrailty with COPD was $56 \%\left(95 \% \mathrm{CI}=52 \%-60 \% ; I^{2}=80.8 \%\right)$ and that of frailty with COPD was $20 \%(95 \% \mathrm{CI}=15 \%-24 \%$; $\left.I^{2}=94.4 \%\right){ }^{37}$

\section{Common pathological pathways and biomarkers for frailty and COPD}

COPD and frailty share some important common risk factors. Cumulative exposure to tobacco, respiratory infections, occupational dust, and air pollution and advanced age can lead to respiratory impairment. In turn, respiratory impairment can increase the risk for adverse outcomes. In addition to respiratory tract symptoms, extrapulmonary manifestations in COPD patients are very similar to the symptoms of frailty, such as fatigue, weight loss, reduced physical activities, muscle weakness, and osteoporosis. Once frailty develops, the AE-COPD, as a new physiological stressor, can result in progressively worsening conditions ranging from disability and morbidity to death. The frequent coexistence of COPD and frailty seems to suggest a common underlying pathophysiological mechanism (see later). ${ }^{29}$

\section{Inflammation}

Inflammation is known to play an important role in the development of COPD. Moreover, chronic inflammation is considered to be one of the primary pathobiological changes driving frailty. ${ }^{38}$ A number of studies have focused on inflammation and frailty. ${ }^{39-43}$ Frail adults have increased serum levels of the proinflammatory cytokine, interleukin-6, compared with non-frail adults, ${ }^{44}$ which has been consistently found to be associated with frailty in both cross-sectional ${ }^{45}$ and prospective studies. ${ }^{39-43}$ The Cardiovascular Health Study (CHS) reported that frail participants had an increased level of C-reactive protein (CRP), ${ }^{42}$ and tumor necrosis factor-alpha and receptors were shown to be associated with frailty. ${ }^{40,46,47}$ Patients with COPD showed signs of chronic inflammation; higher levels of systemic proinflammation 
biomarkers are associated with poorer physical functioning, more exacerbations, and death. ${ }^{48-50}$

\section{Endocrine dysfunction}

Endocrine dysfunction, especially the hypothalamic-pituitary axis, which controls metabolism and energy use through the signaling actions of a series of homoeostatic hormones, ${ }^{51}$ has also been found to be associated with frailty. Frail adults have lower levels of IGF-1, ${ }^{52-56}$ sex hormones, ${ }^{57,58} 25$-hydroxy vitamin $\mathrm{D},{ }^{59-62}$ and dehydroepiandrosterone (DHEA). ${ }^{63,64}$ COPD affects the function of the endocrine system through hypoxemia, hypercapnia, systemic inflammation, and glucocorticoid administration. In turn, altered endocrine function may further contribute to the already aggravated clinical manifestations of COPD. ${ }^{65}$

\section{Sarcopenia}

Clinically, frailty may copresent with sarcopenia. Sarcopenia, defined as an abnormally low lean muscle mass combined with low muscle strength or function, ${ }^{66}$ is a fundamentally important cause of frailty. ${ }^{67}$ The mechanisms underlying sarcopenia include protein and micronutrient deficiencies, chronic inflammation, endocrine dysregulation, and disuse atrophy. ${ }^{68}$ Several studies found that sarcopenia is more common in patients with COPD than in matched healthy controls. ${ }^{69-71}$ In addition, adults with COPD exhibit skeletal muscle dysfunction at the biochemical, cellular, and structural levels. ${ }^{72,73}$ Finally, as the severity of COPD and the concomitant dyspnea worsens, patients can experience decrease in muscle strength, impaired mobility, sarcopenia, and ultimately, frailty.

\section{Assessment tools for frailty used in COPD and clinical practice}

Increasing evidence supports the use of frailty assessment to predict clinical outcomes in patients with chronic lung diseases, especially with COPD (Table 1). Screening for frailty can be used as a prognostic tool to help with treatment decision-making and risk stratification; this will have

Table I Summary of the selected studies on frailty and COPD in different populations

\begin{tabular}{|c|c|c|c|c|c|c|}
\hline $\begin{array}{l}\text { First } \\
\text { author, year } \\
\text { (reference no) }\end{array}$ & $n$ & Country & Design & $\begin{array}{l}\text { Frailty } \\
\text { tool }\end{array}$ & $\begin{array}{l}\text { \% frail with } \\
\text { COPD }\end{array}$ & Main results \\
\hline
\end{tabular}

Based on community dwelling

Vaz Fragoso, 3,578 participants,

$2012^{31} \quad 13.8 \%$ airflow

USA

Cross-sectional FFP

limitation and $9.3 \%$

and longitudinal

No COPD frail data

Pre-frail $48.3 \%$ and

frail $5.8 \%$ in $\mathrm{CHS}$

Frailty and respiratory

restrictive pattern

analysis

data

impairment were strongly

associated with one another.

When frailty and respiratory

impairment were both

present, it will increase the

risk of death

\begin{tabular}{|c|c|c|c|c|c|c|}
\hline $\begin{array}{l}\text { Lahousse, } \\
2016^{29}\end{array}$ & $\begin{array}{l}\text { 2, I } 42 \text { participants, } \\
402 \text { with COPD and } \\
\text { I,740 without COPD }\end{array}$ & The Netherlands & $\begin{array}{l}\text { Prospective } \\
\text { population-based } \\
\text { cohort study }\end{array}$ & FFP & $\begin{array}{l}\text { Pre-frail } 51.2 \% \text { and } \\
\text { frail } 10.2 \%\end{array}$ & $\begin{array}{l}\text { Frailty identified those COPD } \\
\text { participants at high risk of } \\
\text { mortality }\end{array}$ \\
\hline Park, $2013^{6}$ & $\begin{array}{l}20,470 \text { participants, } \\
211 \text { with COPD }\end{array}$ & USA & $\begin{array}{l}\text { Cross-sectional } \\
\text { study }\end{array}$ & TFI & $\begin{array}{l}\text { Pre-frail } 21.8 \% \text { and } \\
\text { frail } 57.8 \%\end{array}$ & $\begin{array}{l}\text { Individuals with COPD who } \\
\text { had self-reported shortness of } \\
\text { breath and comorbid diabetes }\end{array}$ \\
\hline
\end{tabular}

were more likely to be frail

than those who did not. Frail

people tended to have a

greater number of disabilities

\begin{tabular}{|c|c|c|c|c|c|c|}
\hline Galizia, 20 I I 102 & $\begin{array}{l}\text { I,288 (489 with } \\
\text { COPD and } \\
799 \text { without COPD) }\end{array}$ & Italy & $\begin{array}{l}\text { Cross-sectional } \\
\text { study, I2-year } \\
\text { follow-up }\end{array}$ & FSS & $\begin{array}{l}\text { Frailty } 48.9 \% \text { with } \\
\text { COPD and } 36.8 \% \\
\text { without COPD }\end{array}$ & $\begin{array}{l}\text { Clinical frailty COPD had a } \\
\text { high risk of mortality }\end{array}$ \\
\hline Akgün, 201681 & $\begin{array}{l}\text { 3,538 HIV-infected } \\
\text { participants and } \\
3,606 \text { HIV-uninfected } \\
\text { participants, } 4 \% \text { and } \\
5 \% \text { had COPD }\end{array}$ & USA & Cross-sectional & aFRP & $\begin{array}{l}\text { No COPD frail data } \\
\text { Pre-frail } 32.2 \% \text { and } \\
\text { frail } 3.0 \% \text { in HIV } \\
\text { infected; pre-frail } \\
33.0 \% \text { and frail } 2.6 \% \\
\text { in HIV uninfected }\end{array}$ & $\begin{array}{l}\text { COPD was strongly } \\
\text { associated with frailty and } \\
\text { physical limitations. The } \\
\text { association was stronger } \\
\text { among those with both } \\
\text { HIV infection and physical } \\
\text { limitation than among those } \\
\text { without HIV infection }\end{array}$ \\
\hline
\end{tabular}

(Continued) 
Table I (Continued)

\begin{tabular}{|c|c|c|c|c|c|c|}
\hline $\begin{array}{l}\text { First } \\
\text { author, year } \\
\text { (reference no) }\end{array}$ & $\mathbf{n}$ & Country & Design & $\begin{array}{l}\text { Frailty } \\
\text { tool }\end{array}$ & $\begin{array}{l}\% \text { frail with } \\
\text { COPD }\end{array}$ & Main results \\
\hline \multicolumn{7}{|c|}{ Stable COPD outpatients in clinic or rehabilitation center } \\
\hline Gale, $2018^{92}$ & $\begin{array}{l}520 \text { diagnosed with } \\
\text { COPD and I50 } \\
\text { comparator group }\end{array}$ & UK & $\begin{array}{l}\text { Cross-sectional } \\
\text { analysis } \\
\text { Community- } \\
\text { based patients } \\
\text { with COPD }\end{array}$ & FI-CGA & Frail $28 \%$ & $\begin{array}{l}\text { Patients with COPD were } \\
\text { more likely to be frail than } \\
\text { comparators. Frailty could be } \\
\text { predicted by the number of } \\
\text { comorbidities and the number } \\
\text { of exacerbations per year as } \\
\text { well as physical function }\end{array}$ \\
\hline $\begin{array}{l}\text { Limpawattana, } \\
2017^{86}\end{array}$ & I2I COPD patients & Thailand & $\begin{array}{l}\text { Cross-sectional } \\
\text { study of COPD } \\
\text { in clinic }\end{array}$ & FRAIL & $\begin{array}{l}\text { Frail } 6.6 \% \text { and } \\
\text { pre-frail } 41.3 \%\end{array}$ & $\begin{array}{l}\text { Fatigue was the major } \\
\text { component of frailty in these } \\
\text { populations }\end{array}$ \\
\hline $\begin{array}{l}\text { Kusunose, } \\
2017^{96}\end{array}$ & 79 COPD patients & Japan & $\begin{array}{l}\text { Prospective, } \\
\text { consecutive } \\
\text { COPD } \\
\text { outpatients }\end{array}$ & $\mathrm{KCL}$ & $\begin{array}{l}\text { Pre-frail } 30.4 \% \text { and } \\
\text { frail } 21.5 \%\end{array}$ & $\begin{array}{l}\text { Frailty was significantly related } \\
\text { with SGRQ. Frailty assessment } \\
\text { should be included in the } \\
\text { multidimensional assessment } \\
\text { of COPD and separated from } \\
\text { lung function assessment }\end{array}$ \\
\hline Mittal, $2016^{28}$ & $\begin{array}{l}\text { I20 participants with } \\
\text { chronic lung disease, } \\
56 \% \text { with COPD }\end{array}$ & USA & Prospective & FFP & $\begin{array}{l}\text { Pre-frail } 64 \% \text { and } \\
\text { frail } 18 \%\end{array}$ & $\begin{array}{l}\text { Frailty was common in } \\
\text { patients with chronic lung } \\
\text { diseases. Exhaustion and slow } \\
\text { gait speed were the two most } \\
\text { common markers of frailty }\end{array}$ \\
\hline $\begin{array}{l}\text { Maddocks, } \\
2016^{32}\end{array}$ & 816 & UK & Prospective & FFP & $\begin{array}{l}\text { Pre-frail } 64.3 \% \text { and } \\
\text { frail } 25.6 \%\end{array}$ & $\begin{array}{l}\text { Frail patients responded } \\
\text { favorably to rehabilitation, and } \\
\text { their frailty can be reversed in } \\
\text { the short term }\end{array}$ \\
\hline \multicolumn{7}{|c|}{ Clinically advanced COPD in hospital } \\
\hline Baldwin, $2017^{79}$ & $\begin{array}{l}618 \text { with advanced } \\
\text { lung disease, } \\
130 \text { older ICU } \\
\text { survivors }\end{array}$ & USA & $\begin{array}{l}\text { Prospective, } \\
\text { multicenter } \\
\text { cohort }\end{array}$ & $\begin{array}{l}\text { FFP- } \\
\text { MLTA } \\
\text { and FFP- } \\
\text { DASI }\end{array}$ & $\begin{array}{l}\text { Advanced frail } \\
42 \%-1 \% \text { and ICU } \\
49 \%-12 \%\end{array}$ & $\begin{array}{l}\text { MLTA had a substantially } \\
\text { greater floor effect than the } \\
\text { DASI. The DASI improved } \\
\text { the construct and predictive } \\
\text { validity of frailty assessment }\end{array}$ \\
\hline $\begin{array}{l}\text { Uchmanowicz, } \\
2016^{4}\end{array}$ & 102 & Poland & $\begin{array}{l}\text { Prospective, } \\
\text { hospitalized due } \\
\text { to exacerbation }\end{array}$ & TFI & $75.5 \%$ & $\begin{array}{l}\text { Elderly patients with severe } \\
\text { COPD may be more prone } \\
\text { to frailty and decreased } \\
\text { acceptance of their disease } \\
\text { in comparison to patients } \\
\text { suffering from other chronic } \\
\text { diseases }\end{array}$ \\
\hline $\begin{array}{l}\text { Bernabeu-Mora, } \\
2017^{99}\end{array}$ & 103 & Spain & $\begin{array}{l}\text { Prospective, } \\
\text { hospitalized }\end{array}$ & REFS & $\begin{array}{l}\text { Mild frailty } 25 \% \text {, } \\
\text { moderate frailty } \\
27.8 \% \text {, and severe } \\
\text { frailty } 66.7 \% \\
\end{array}$ & $\begin{array}{l}\text { Identifying patients with frailty } \\
\text { for targeted interventions may } \\
\text { reduce early readmission rates }\end{array}$ \\
\hline Valenza, 2016 121 & $\begin{array}{l}212 \text { (104 stable and } \\
108 \text { exacerbation) }\end{array}$ & Spain & $\begin{array}{l}\text { Cross-sectional } \\
\text { study }\end{array}$ & $\begin{array}{l}\text { Modified } \\
\text { FFP } \\
\text { Modified } \\
\text { Baecke } \\
\text { physical } \\
\text { activity }\end{array}$ & $\begin{array}{l}\text { Stable } 64.8 \% \text { and } \\
\text { exacerbation } 62.6 \%\end{array}$ & $\begin{array}{l}\text { Physical activity level can } \\
\text { predict the absence or } \\
\text { presence of frailty in subjects } \\
\text { with stable and exacerbated } \\
\text { COPD }\end{array}$ \\
\hline
\end{tabular}

Abbreviations: aFRP, adapted frailty-related phenotype; COPD, chronic obstructive pulmonary disease; FFP, Fried frailty phenotype; CHS, Cardiovascular Health Study; TFI, Tilburg Frailty Indicator; FSS, Frailty Staging System; FI, Frailty Index; CGA, Comprehensive Geriatric Assessment; KCL, Kihon Checklist; SGRQ, St George's Respiratory Questionnaire; MLTA, Minnesota Leisure Time Physical Activity Questionnaire; DASI, Duke Activity Scale Index; REFS, Reported Edmonton Frail Scale.

importance in differentiating patients who will benefit from the treatment from those who may obtain no benefit or even experience harmful consequences from interventions and pulmonary rehabilitation. ${ }^{32,74}$

\section{Fried frailty phenotype (FFP)}

Most studies involving the interactions between COPD and frailty were assessed by the FFP. The FFP, ${ }^{75}$ often known as the CHS index, has five core domains, including slowness 
(slow gait speed), weakness (low grip strength), low physical activity (Minnesota Leisure Time Activity), exhaustion (Center for Epidemiologic Studies-Depression [CES-D] questionnaire), and weight loss (self-reported weight loss of $4.5 \mathrm{~kg}$ or recorded weight loss of 5\% in the last year). Patients with 3-5, $1-2$, and 0 factors are classified as frail, pre-frail, and robust, respectively. The FFP is the most frequently cited frailty tool ${ }^{76}$ and has been used to predict mortality and adverse clinical outcomes in large cohorts of community-dwelling elders. ${ }^{77,78}$

In the following, we describe several studies to demonstrate the relevance and impact of FFP frailty assessment; these studies were each carried out with a different participant group, ie, community-based, stable COPD outpatients, and advanced COPD in hospital and immunodeficient patient group, respectively.

\section{Community-based population}

Vaz Fragoso et $\mathrm{al}^{31}$ used the CHS data for their communitybased, large population study and evaluated the relationship between a modified version of the FFP and respiratory impairment in 3,578 participants; respiratory impairment included airflow limitation or restriction as measured by spirometry using contemporary protocols of the American Thoracic Society. Participants completed a battery of assessments at baseline and 4 years thereafter and underwent up to 12 years of vital status follow-up evaluations. After adjusting for relevant covariates, pre-frail and frail participants were found to have a $42 \%$ higher likelihood of developing respiratory impairment than participants who were non-frail. Conversely, participants with respiratory impairment at baseline had a 58\% higher likelihood of developing pre-frailty or frailty than participants without respiratory impairment at baseline. The impact of baseline respiratory impairment and frailty status on mortality appeared to be synergistic as well. Compared with non-frail subjects with normal respiratory function, frail subjects with respiratory impairment had a nearly fourfold higher risk for death. The risk for death was at least twofold higher for frail subjects with respiratory impairment than that for non-frail subjects with respiratory impairment or frail subjects without respiratory impairment. Another population-based study evaluated 2,142 community-dwelling older adults (402 with COPD and 1,740 without COPD) who had an FFP assessment and underwent spirometry. ${ }^{29}$ The participants with COPD were more than twice as likely to be frail as those without COPD; this association was stronger with COPD of increased severity according to the Global Initiative for Chronic Obstructive Lung Disease (GOLD) criteria. During an average follow-up of 805 days, frail participants with COPD had a nearly threefold higher mortality rate than non-frail participants without COPD. Notably, frailty status was a stronger determinant of mortality than the $\mathrm{FEV}_{1} \%$ or comorbidity.

\section{Stable COPD outpatients}

FFP was also used for assessing frailty in stable COPD outpatients. Mittal et $\mathrm{al}^{28}$ reported that frailty is relatively common in ambulatory patients with chronic lung diseases recruited from clinics and a rehabilitation center. Patients with COPD accounted for $56 \%$ of the total patients. Frail patients had higher self-reported hospitalizations and falls and lower gait speeds. Based on FFP, self-reported exhaustion $(90.5 \%)$ and slow gait speed $(76.2 \%)$ were the most common frailty criteria. The simple screening tool, gait speed, can be used to screen frail patients with a high sensitivity but a low specificity. To evaluate the rehabilitation outcomes of stable COPD outpatients, a study ${ }^{32}$ showed that frail patients with stable COPD appropriate for a pulmonary rehabilitation referral had more difficulty engaging in pulmonary rehabilitation. Frailty is both a strong and an independent risk factor for failure to complete pulmonary rehabilitation than smoking status, breathlessness, or low mood. Although frail patients with COPD were more unlikely to complete rehabilitation, the frailty phenotype was reversed for stable COPD patients who did complete pulmonary rehabilitation. In addition, they appeared to have more favorable rehabilitation outcomes, including physical, psychological, and global health improvement. ${ }^{32}$ Therefore, proactively screening frail stable COPD patients and researching a better means to support frail patients through rehabilitation will direct clinicians to make a greater effort to identify suitable patients for pulmonary rehabilitation referral who are more likely to benefit from the intervention.

\section{Clinically advanced and critical patients}

For frailty assessment in patients with advanced and critical lung disease, the FFP has limitations. Baldwin et $\mathrm{al}^{79}$ showed that the Minnesota Leisure Time Physical Activity Questionnaire (MLTA) has a significant floor effect in patients with advanced lung disease and in critical care survivors. In this study, ${ }^{79}$ they measured frailty physical activity using the Duke Activity Scale Index (DASI) and the MLTA in two cohorts of patients (advanced lung disease patients awaiting lung transplantation and survivors of acute respiratory failure). The results ${ }^{79}$ showed that the DASI performed better and had a less pronounced floor effect than MLTA in this patient population and was more predictive of frailty outcome. The DASI queries activities more relevant to adults with 
advanced lung disease or to survivors of critical illness, and thus can minimize misclassification of frailty attributable to low activity and can better discriminate between different levels of activities relevant to the fields of pulmonary and critical care medicine. ${ }^{79}$ The FFP is based on the experience of suburban community-dwelling older adults who had fewer activity limitations than adults with advanced lung disease or older survivors of acute respiratory failure. ${ }^{79}$ Because of this fundamental context, it is perhaps not surprising to see that FFP has proven limited utility for the care of this category of patients.

\section{Immunodeficient population}

An adapted FFP (Multicenter AIDS Cohort Study [MACS]based survey with four domains [physical shrinking, exhaustion, slowness, and decreased physical activity]) was used to measure frailty in an immunodeficient population drawn from the Veterans Aging Cohort Study (VACS) by comparing HIVinfected individuals with HIV-uninfected individuals. COPD was an independent risk factor for frailty in HIV-infected patients $;{ }^{80}$ it was diagnosed in $4 \%$ of $3,538 \mathrm{HIV}$-infected participants and $5 \%$ of $3,606 \mathrm{HIV}$-uninfected participants. Using the adapted frailty-related phenotype (aFRP) assessment tool, $59 \%$ of HIV-infected patients and $58 \%$ of HIV-uninfected patients with COPD met the criteria for pre-frailty vs $34 \%$ of HIV-infected patients and HIV-uninfected patients without COPD. The association between COPD and the physical limitation scale was stronger in HIV-infected participants compared with HIV-uninfected participants. ${ }^{81}$

Overall, FFP is a practical assessment tool for frailty patients with COPD and has been widely adopted by the research and clinical communities.

\section{FRAIL scale}

FRAIL, proposed by the International Association of Nutrition and Aging, ${ }^{82}$ comprises five components (fatigue, resistance, ambulation, illness, and loss of weight). FRAIL is administered in the format of a simple, self-report questionnaire based on the phenotype model. Patients reporting $3-5,1-2$, and 0 factors are classified as frail, pre-frail, and robust, respectively. In addition, FRAIL is an independent risk factor for predicting mortality and adverse outcomes in specific populations. ${ }^{83-85}$

Using the FRAIL scale, a cross-sectional study in Thailand reported that the prevalence of frailty in COPD patients was $6.6 \%$. Each component of the FRAIL scale showed a greater rate in frail patients than that in non-frail patients, and fatigue was the main factor of frailty in these populations.
Interestingly, this study was a sub-study of "Sarcopenia in COPD", which found that sarcopenia was indeed associated with frailty. Therefore, in theory, frail COPD patients might benefit from the prevention of sarcopenia. ${ }^{86}$ Although the FRAIL scale is a simple, self-report tool to measure frailty based on the phenotype, there have not been any validated studies involving hospitalized participants.

\section{Frailty Index (FI) and the FI derived from a Comprehensive Geriatric Assessment (FI-CGA)}

The Rockwood Accumulative Deficits Index, ${ }^{87}$ also referred to as the FI, was developed on the basis of the Canadian Study of Health and Aging (CSHA) as a multidimensional measure of frailty. The FI expresses the theory of gradation of frailty with progressive accumulation of deficits, each of which has an equal weight in mathematical modeling $;{ }^{88}$ FI involves the accumulation of 20-70 age-related indicators of health, including comorbidities, symptoms, diseases, disabilities, or any deficiency in health. ${ }^{89}$ The deficit model enables the use of clinical data collected from medical records for frailty assessment, thus making it possible to identify frail elderly people who will achieve improved outcomes from interventions..$^{90}$ Despite this, the calculation of FI is time consuming, and its mathematical nature renders the FI unpopular in clinics. ${ }^{91} \mathrm{CGA}$ is the global standard clinical assessment for older people. FI-CGA is a simple FI using data from a CGA. The FI-CGA was calculated by dividing the total number of CGA deficits.

In a community-based cross-sectional analysis, all participants, including 520 patients diagnosed with COPD and 150 comparators, completed a modified version of the CGA questionnaire. Using FI-CGA assessment and the age-adjusted cutoff for frailty from the Survey of Health, Aging, and Retirement in Europe, the study showed that the prevalence of frailty was $28 \%$ in COPD patients and $0 \%$ in comparators. Frail participants also had poorer lung function and physical activity (handgrip and 6-minute walking distance), greater inflammation (fibrinogen and high-sensitivity CRP) and more exacerbations, symptoms, and a poorer health-related quality of life than comparators. $^{92}$

\section{Kihon Checklist (KCL)}

$\mathrm{KCL}$ is a validated frailty measurement tool consisting of $25 \mathrm{yes} /$ no questions proposed by the Ministry of Health, Labor, and Welfare of Japan. ${ }^{93}$ The 25 self-report 
questions are grouped into seven categories including instrumental (three scores) and social activities of daily living (four scores), physical functions (five scores), nutritional status (two scores), oral function (three scores), cognitive functions (three scores), and mood (five scores) ${ }^{94}$ The KCL showed predictive utility for the incidence of dependency and mortality in community-dwelling older people..$^{95}$

Using the KCL frailty assessment tool, Kusunose et a ${ }^{96}$ showed a significant association between frailty status and St George's Respiratory Questionnaire in patients with stable COPD. Frailty appeared to have developed via an independent mechanism except for age-related deterioration in patients with COPD. Frailty assessment was recommended to be included as a part of multidimensional measurements of COPD. ${ }^{96}$ However, similar to FRAIL scale, further validation studies of the KCL in hospitalized COPD patients need to be undertaken.

\section{Edmonton Frail Scale (EFS) and Reported Edmonton Frail Scale (REFS)}

The EFS, extracted from CGAs, is a valid and reliable screening tool for the identification of frailty. The EFS has a maximum score of 17 and consists of the following domains: cognition, general health status, functional independence, social support, medication use, mood, continence, nutrition, and functional performance. ${ }^{97}$ The REFS adapted the domain "get up and go" to a report of physical function, which was developed in acute care. The reported physical function increased the functional score, and therefore, the component scores are summed from items 1 to 18 . The severity of frailty is classified as follows: "not frail (0-5), apparently vulnerable (6-7), mildly frail (8-9), moderately frail (10-11), and severe frailty $(12-18) " .98$

A prospective study was designed to observe COPD patients hospitalized with exacerbations in acute medical wards and during follow-up within 90 days after hospital discharge. Frailty of patients with AE-COPD was assessed within 48-96 hours of hospital admission using the REFS. Frailty was categorized into the following four predefined categories: not frail or vulnerable (44.7\%), mild frailty (19.4\%), moderate frailty $(17.5 \%)$, and severe frailty $(18.4 \%)$. The 90-day readmission rates were found to increase with the severity of frailty. Patients with "severe frailty" were approximately fivefold more likely to have readmission than those with "non-frail" status. In addition, frailty was an independent predictor of readmission within 90 days in patients with AE-COPD. ${ }^{99}$

\section{Frailty Staging System (FSS)}

The FSS, as an index of functional impairment severity, was modified from a previous screening method for functional disability in elderly people. ${ }^{100}$ The FSS covers the following seven core categories: disability, mobility, cognitive function, visual function, hearing function, urinary continence, and social support. ${ }^{101}$

The FSS frailty assessment tool was used in a study involving 489 patients with COPD with a follow-up period of 12 years. ${ }^{102}$ The severity of frailty was classified according to the number of frail domains: mild, one domain; moderate, two or three domains; and severe, four or more domains. Mortality was increased from $48.1 \%$ in patients without COPD to $60.7 \%$ in patients with COPD. In patients with increasing severity of frailty, mortality increased from $54.3 \%$ in patients without COPD to $97.0 \%$ in patients with COPD. Therefore, clinical frailty may be considered as a prognostic factor when identifying COPD patients at high risk for mortality. ${ }^{102}$

\section{Tilburg Frailty Indicator (TFI)}

The TFI has been proven to have good validity and reliability for community-dwelling older people. ${ }^{103}$ The TFI is an easyto-administer questionnaire based on an integral conceptual model of frailty containing 15 self-report categories (eleven "yes/no" questions and four "sometimes" questions). The TFI refers to the following three categories of frailty: physical frailty (health, unexplained weight loss, difficulty in walking, balance, poor hearing, vision, lack of strength in the hands, and tiredness), psychological frailty (problems with memory, feeling down, anxiety, and inability to cope with problems), and social frailty (living alone, lack of social relations, and social support). A score $>5$ is the best cutoff point indicative of frailty. ${ }^{104,105}$

Nine-item criteria modified from the TFI were used in a community-based study that included 211 participants with COPD and a history of smoking from the National Health and Nutrition Evaluation Survey (NHANES) dataset (2003-2006) of 20,470 participants. ${ }^{6}$ Of the 211 participants, $57.8 \%$ were diagnosed with frailty among the participants with COPD. The study showed that patients with COPD who had shortness of breath were more likely to be frail than patients who did not have COPD. Frail people with COPD were associated with impairments in activities of daily living/ instrumental activities of daily living.

Uchmanowicz et al used the TFI to evaluate the association between the level of acceptance of illness and frailty in 102 COPD patients hospitalized with an exacerbation. 
Frailty was diagnosed in $>75 \%$ of the COPD patient group. Elderly patients with severe COPD were more prone to frailty and had lower levels of disease acceptance than other chronic diseases. Patients with a higher level of frailty in physical and social domains correlated with a lower level of acceptance of illness. ${ }^{4}$

\section{Summary}

Frailty evaluation in patients with COPD is a feasible prognostic utility for mortality and hospitalization. Physical frailty screening may help identify those patients who will be more likely to benefit from available interventions for other illnesses as shown in the study with frail COPD patients. ${ }^{31}$

The FFP is the most widely used frailty assessment tool and has been validated in many studies. However, in the case of severe COPD exacerbations, it is still very difficult to predict intensive care unit (ICU) outcomes. Identifying patients who are likely or indeed unlikely to benefit from admission to ICU wards would greatly improve the quality of care provided to these patients, enable patients to make better advance directives and allow health care workers to offer palliative care in a timely manner to patients with a high risk for severe morbidity and mortality. As a first step, it is a reasonable strategy to consider using various tools, in their original or modified form, or with different cutoff values to evaluate the effect of frailty on outcomes from intervention delivered to the specific populations.

\section{Intervention}

Frailty is an independent risk factor for exacerbations and progression of COPD, and patients with COPD are also more prone to frailty. Although frailty and COPD affect each other, both frailty and respiratory impairment can be modulated and treated. When one is treated and/or prevented, the other may be improved. Therefore, a more thorough understanding of the relationship between frailty and COPD can help clinicians better prevent and intervene in patients with these two conditions and may reduce the occurrence of poor outcomes. ${ }^{31}$

Muscle wasting, weakness, and malnutrition are common in patients with lung disease and could be responsive to physical exercise training and nutrition optimization. This underscores the importance of rehabilitation. Moreover, pulmonary rehabilitation has been shown to reverse frail patients with COPD who responded well to treatment. ${ }^{32}$ Similarly, many factors related to frailty can also be improved through prevention and supportive treatment, such as suitable exercise and nutritional support. Positive treatment effects among these frailty constructs may partially explain why pulmonary rehabilitation improves exercise capacity, disability, and health-related quality of life and reduces hospitalizations and mortality. ${ }^{106,107}$ Recent work in older populations has shown that frailty may be reversible through targeted exercise and nutritional interventions. ${ }^{108-110}$ It has been postulated that nutritional interventions may be suitable for frail patients with nutritional deficiency and weight loss; however, the evidence for this has been scarce. A systematic review showed that sustained nutritional supplementation had no significant effect on pulmonary function, respiratory muscle strength, and functional exercise capacity in patients with stable COPD. ${ }^{111}$ Individual nutrition supplementation may not be able to reverse the decline in muscle strength and function if the intervention is given too late. ${ }^{12,113}$ Further research is needed to determine what constitutes effective nutrition interventions. ${ }^{114}$

Some studies have reported the effects of various pharmacotherapies targeting the biological frailty pathway, including angiotensin-converting enzyme inhibitors, ${ }^{115}$ DHEA, testosterone, recombinant human growth hormone, ${ }^{116}$ and vitamin D. ${ }^{117}$ There are no sufficient data to recommend any of these agents for routine use.

There is increasing evidence to support the notion that a comprehensive assessment can help to mitigate the risk factors associated with frailty. ${ }^{118,119}$ Frailty and pre-frailty are common in patients with COPD; however, using multidisciplinary intervention, patients with frailty can be reversed, especially at the pre-frailty stage. ${ }^{120}$ Therefore, it is critical to diagnose frailty at an early stage. Furthermore, early intervention through comprehensive assessments, referral exercise, and nutritional interventions would prevent and delay the progression of frailty.

\section{Conclusion}

Frailty and COPD have a strong association in aged population. Treating the frailty syndrome will likely reduce risk for poor COPD outcomes. Early recognition of frailty is important in patients with COPD, as early and effective interventions can prevent or delay functional deterioration, institutionalization, disability, and death. Assessment of frail COPD patients can provide better stratification of risks and individual management and improve patient outcomes. There remains controversy in the literature regarding the best frailty assessment tool in older adults with COPD. Some frailty assessment tools are suitable for screening the health status of community populations, whereas others are suitable for assessing outpatients or emergency patients. Further research in this field is warranted, and it should target specific 
patient groups in order to establish more effective assessment tools, which would improve the effectiveness of screening and identifying patients at different stages of frailty, thus allowing health care workers to apply individual-specific treatment regimen.

\section{Acknowledgment}

This work was supported by a grant from the National Natural Science Foundation of China (No 81201832) and the Natural Science Foundation of Liaoning Province (No 201602846).

\section{Disclosure}

The authors report no conflicts of interest in this work.

\section{References}

1. Song X, Mitnitski A, Rockwood K, Prevalence RK. Prevalence and 10 -year outcomes of frailty in older adults in relation to deficit accumulation. J Am Geriatr Soc. 2010;58(4):681-687.

2. Xue Q-L. The frailty syndrome: definition and natural history. Clin Geriatr Med. 2011;27(1):1-15.

3. Bergman H, Ferrucci L, Guralnik J, et al. Frailty: an emerging research and clinical paradigm - issues and controversies. J Gerontol A Biol Sci Med Sci. 2007;62(7):731-737.

4. Uchmanowicz I, Jankowska-Polańska B, Chabowski M, Uchmanowicz B, $\mathrm{Fal}$ AM. The influence of frailty syndrome on acceptance of illness in elderly patients with chronic obstructive pulmonary disease. Int J Chron Obstruct Pulmon Dis. 2016;11:2401-2407.

5. Díaz de León González E, Gutiérrez Hermosillo H, Martinez Beltran JA, et al. Validation of the FRAIL scale in Mexican elderly: results from the Mexican Health and Aging Study. Aging Clin Exp Res. 2016; 28(5):901-908.

6. Park SK, Richardson CR, Holleman RG, Larson JL. Frailty in people with COPD, using the National Health and Nutrition Evaluation Survey dataset (2003-2006). Heart \& Lung: The Journal of Acute and Critical Care. 2013;42(3):163-170.

7. Woo J, Yu R, Wong M, Yeung F, Wong M, Lum C. Frailty screening in the community using the FRAIL scale. J Am Med Dir Assoc. 2015; 16(5):412-419.

8. Masel MC, Graham JE, Reistetter TA, Markides KS, Ottenbacher KJ. Frailty and health related quality of life in older Mexican Americans. Health Qual Life Outcomes. 2009;7(1):70.

9. Mitnitski AB, Graham JE, Mogilner AJ, Rockwood K. Frailty, fitness and late-life mortality in relation to chronological and biological age. BMC Geriatr. 2002;2(1):1.

10. Carlson JE, Zocchi KA, Bettencourt DM, et al. Measuring frailty in the hospitalized elderly: concept of functional homeostasis. Am J Phys Med Rehabil. 1998;77(3):252-257.

11. Ma L, Zhang L, Tang Z, et al. Use of the frailty index in evaluating the prognosis of older people in Beijing: a cohort study with an 8-year follow-up. Arch Gerontol Geriatr. 2016;64:172-177.

12. Joosten E, Demuynck M, Detroyer E, Milisen K. Prevalence of frailty and its ability to predict in hospital delirium, falls, and 6-month mortality in hospitalized older patients. BMC Geriatr. 2014;14(1):1.

13. Clegg A, Young J, Iliffe S, Rikkert MO, Rockwood K. Frailty in elderly people. Lancet. 2013;381(9868):752-762.

14. Morley JE, Vellas B, van Kan GA, Abellan van Kan G, et al. Frailty consensus: a call to action. J Am Med Dir Assoc. 2013;14(6):392-397.

15. Vaughan L, Goveas J, Corbin A. Depression and frailty in later life: a systematic review. Clin Interv Aging. 2015;10:1947-1958.
16. Ma L, Tang Z, Zhang L, Sun F, Li Y, Chan P. Prevalence of frailty and associated factors in the community-dwelling population of China. J Am Geriatr Soc. 2018;66(3):559-564.

17. Mcnallan SM, Singh M, Chamberlain AM, et al. Frailty and healthcare utilization among patients with heart failure in the community. JACC Heart Fail. 2013;1(2):135-141.

18. Singer JP, Lederer DJ, Baldwin MR. Frailty in pulmonary and critical care medicine. Ann Am Thorac Soc. 2016;13(8):1394-1404.

19. Walston J, Robinson TN, Zieman S, et al. Integrating frailty research into the medical specialties - Report from a U13 conference. J Am Geriatr Soc. 2017;65(10):2134-2139.

20. Vogelmeier CF, Criner GJ, Martínez FJ, et al. Global Strategy for the Diagnosis, Management, and Prevention of Chronic Obstructive Lung Disease 2017 Report: GOLD Executive Summary. Arch Bronconeumol. 2017;53(3):128-149.

21. Gifcol D. Global Strategy for the Diagnosis, Management and Prevention of COPD. Global Initiative for Chronic Obstructive Lung Disease. 2018. http://www.goldcopd.org

22. Mathers CD, Loncar D. Projections of global mortality and burden of disease from 2002 to 2030. PLoS Med. 2006;3(11):e442.

23. Uchmanowicz I, Lisiak M, Wontor R, et al. Frailty syndrome in cardiovascular disease: clinical significance and research tools. Eur $J$ Cardiovasc Nurs. 2015;14(4):303-309.

24. Blaum CS, Xue QL, Michelon E, Semba RD, Fried LP. The association between obesity and the frailty syndrome in older women: the Women's Health and Aging Studies. J Am Geriatr Soc. 2005;53(6): 927-934.

25. Bohm C, Storsley L, Tangri N. The assessment of frailty in older people with chronic kidney disease. Curr Opin Nephrol Hypertens. 2015;24(6):498-504.

26. Luckhardt T, Thannickal VJ. Measures of frailty in chronic lung diseases. Ann Am Thorac Soc. 2017;14(8):1266-1267.

27. Milne KM, Kwan JM, Guler S, et al. Frailty is common and strongly associated with dyspnoea severity in fibrotic interstitial lung disease. Respirology. 2017;22(4):728-734.

28. Mittal N, Raj R, Islam EA, Nugent K. The frequency of frailty in ambulatory patients with chronic lung diseases. J Prim Care Community Health. 2016;7(1):10-15.

29. Lahousse L, Ziere G, Verlinden VJA, et al. Risk of frailty in elderly with COPD: a population-based study. J Gerontol A Biol Sci Med Sci. 2016;71(5):689-695.

30. Singer JP, Diamond JM, Gries CJ, et al. Frailty phenotypes, disability, and outcomes in adult candidates for lung transplantation. Am J Respir Crit Care Med. 2015;192(11):1325-1334.

31. Vaz Fragoso CA, Enright PL, Mcavay G, van Ness PH, Gill TM. Frailty and respiratory impairment in older persons. Am J Med. 2012; 125(1):79-86.

32. Maddocks M, Kon SSC, Canavan JL, et al. Physical frailty and pulmonary rehabilitation in COPD: a prospective cohort study. Thorax. 2016;71(11):988-995.

33. Shamliyan T, Talley KMC, Ramakrishnan R, Kane RL. Association of frailty with survival: a systematic literature review. Ageing Res Rev. 2013;12(2):719-736.

34. van Iersel MB, Rikkert MG. Frailty criteria give heterogeneous results when applied in clinical practice. J Am Geriatr Soc. 2006;54(4): 728-729.

35. Collard RM, Boter H, Schoevers RA, Oude Voshaar RC. Prevalence of frailty in community-dwelling older persons: a systematic review. J Am Geriatr Soc. 2012;60(8):1487-1492.

36. Tom SE, Adachi JD, Anderson FA, et al. Frailty and fracture, disability, and falls: a multiple country study from the global longitudinal study of osteoporosis in women. J Am Geriatr Soc. 2013;61(3):327-334.

37. Marengoni A, Vetrano DL, Manes-Gravina E, Bernabei R, Onder G, Palmer K. The relationship between COPD and frailty: a systematic review and meta-analysis of observational studies. Chest. 2018;154(1):21-40.

38. Chen X, Mao G, Leng SX. Frailty syndrome: an overview. Clin Interv Aging. 2014;9:433-441. 
39. Hubbard RE, O'Mahony MS, Calver BL, Woodhouse KW. Nutrition, inflammation, and leptin levels in aging and frailty. J Am Geriatr Soc. 2008;56(2):279-284.

40. Hubbard RE, O'Mahony MS, Savva GM, Calver BL, Woodhouse KW. Inflammation and frailty measures in older people. J Cell Mol Med. 2009;13(9b):3103-3109.

41. Cesari M, Penninx BWJH, Pahor M, et al. Inflammatory markers and physical performance in older persons: the InCHIANTI study. J Gerontol A Biol Sci Med Sci. 2004;59(3):M242-M248.

42. Walston J, Mcburnie MA, Newman A, et al. Frailty and activation of the inflammation and coagulation systems with and without clinical comorbidities: results from the Cardiovascular Health Study. Arch Intern Med. 2002;162(20):2333-2341.

43. Barzilay JI, Blaum C, Moore T, et al. Insulin resistance and inflammation as precursors of frailty: the Cardiovascular Health Study. Arch Intern Med. 2007;167(7):635-641.

44. Leng S, Chaves P, Koenig K, Walston J. Serum interleukin-6 and hemoglobin as physiological correlates in the geriatric syndrome of frailty: a pilot study. J Am Geriatr Soc. 2002;50(7):1268-1271.

45. Matheï C, Vaes B, Wallemacq P, Degryse J. Associations between cytomegalovirus infection and functional impairment and frailty in the BELFRAIL cohort. J Am Geriatr Soc. 2011;59(12):2201-2208.

46. Serviddio G, Romano AD, Greco A, et al. Frailty syndrome is associated with altered circulating redox balance and increased markers of oxidative stress. Int J Immunopathol Pharmacol. 2009;22(3):819-827.

47. Varadhan R, Yao W, Matteini A, et al. Simple biologically informed inflammatory index of two serum cytokines predicts 10 year allcause mortality in older adults. J Gerontol A Biol Sci Med Sci. 2014; 69A(2):165-173.

48. Agustí A, Edwards LD, Rennard SI, et al. Persistent systemic inflammation is associated with poor clinical outcomes in COPD: a novel phenotype. PLoS One. 2012;7(5):e37483.

49. Karadag F, Karul AB, Cildag O, Yilmaz M, Ozcan H. Biomarkers of systemic inflammation in stable and exacerbation phases of COPD. Lung. 2008;186(6):403-409.

50. Thomsen M, Ingebrigtsen TS, Marott JL, et al. Inflammatory biomarkers and exacerbations in chronic obstructive pulmonary disease. JAMA. 2013;309(22):2353-2361.

51. Bishop NA, Lu T, Yankner BA. Neural mechanisms of ageing and cognitive decline. Nature. 2010;464(7288):529-535.

52. Leng SX, Hung W, Cappola AR, Yu Q, Xue QL, Fried LP. White blood cell counts, insulin-like growth factor-1 levels, and frailty in community-dwelling older women. J Gerontol A Biol Sci Med Sci. 2009; 64(4):499-502.

53. Cappola AR, Xue QL, Ferrucci L, Guralnik JM, Volpato S, Fried LP. Insulin-like growth factor I and interleukin-6 contribute synergistically to disability and mortality in older women. J Clin Endocrinol Metab. 2003;88(5):2019-2025.

54. Leng SX, Cappola AR, Andersen RE, et al. Serum levels of insulin-like growth factor-I (IGF-I) and dehydroepiandrosterone sulfate (DHEA-S), and their relationships with serum interleukin-6, in the geriatric syndrome of frailty. Aging Clin Exp Res. 2004;16(2):153-157.

55. Cawthon PM, Ensrud KE, Laughlin GA, et al. Sex hormones and frailty in older men: the osteoporotic fractures in men (MrOS) study. J Clin Endocrinol Metab. 2009;94(10):3806-3815.

56. Joseph C, Kenny AM, Taxel P, Lorenzo JA, Duque G, Kuchel GA. Role of endocrine-immune dysregulation in osteoporosis, sarcopenia, frailty and fracture risk. Mol Aspects Med. 2005;26(3):181-201.

57. Hyde Z, Flicker L, Almeida OP, et al. Low free testosterone predicts frailty in older men: the health in men study. J Clin Endocrinol Metab. 2010;95(7):3165-3172.

58. Eichholzer M, Barbir A, Basaria S, et al. Serum sex steroid hormones and frailty in older American men of the Third National Health and Nutrition Examination Survey (NHANES III). Aging Male. 2012;15(4):208-215.

59. Puts MTE, Visser M, Twisk JWR, Deeg DJH, Lips P. Endocrine and inflammatory markers as predictors of frailty. Clin Endocrinol. 2005; 63(4):403-411.
60. Tiidus PM, Lowe DA, Brown M. Estrogen replacement and skeletal muscle: mechanisms and population health. J Appl Physiol. 2013; 115(5):569-578.

61. Travison TG, Nguyen A-H, Naganathan V, et al. Changes in reproductive hormone concentrations predict the prevalence and progression of the frailty syndrome in older men: the concord health and ageing in men project. J Clin Endocrinol Metab. 2011;96(8):2464-2474.

62. Shardell M, Hicks GE, Miller RR, et al. Association of low vitamin D levels with the frailty syndrome in men and women. J Gerontol A Biol Sci Med Sci. 2009;64A(1):69-75.

63. Haren MT, Malmstrom TK, Banks WA, Patrick P, Miller DK, Morley JE. Lower serum DHEAS levels are associated with a higher degree of physical disability and depressive symptoms in middle-aged to older African American women. Maturitas. 2007;57(4):347-360.

64. Voznesensky M, Walsh S, Dauser D, Brindisi J, Kenny AM. The association between dehydroepiandosterone and frailty in older men and women. Age Ageing. 2009;38(4):401-406.

65. Laghi F, Adiguzel N, Tobin MJ. Endocrinological derangements in COPD. Eur Respir J. 2009;34(4):975-996.

66. Cesari M, Landi F, Vellas B, Bernabei R, Marzetti E. Sarcopenia and physical frailty: two sides of the same coin. Front Aging Neurosci. 2014;6:192.

67. Studenski SA, Peters KW, Alley DE, et al. The FNIH sarcopenia project: rationale, study description, conference recommendations, and final estimates. J Gerontol A. 2014;69(5):547-558.

68. Morley JE. Sarcopenia in the elderly. Fam Pract. 2012;29(Suppl 1): i44-i48.

69. Schols AMWJ, Broekhuizen R, Weling-Scheepers CA, Wouters EF. Body composition and mortality in chronic obstructive pulmonary disease. Am J Clin Nutr. 2005;82(1):53-59.

70. Jones SE, Maddocks M, Kon SSC, et al. Sarcopenia in COPD: prevalence, clinical correlates and response to pulmonary rehabilitation. Thorax. 2015;70(3):213-218.

71. Greening NJ, Harvey-Dunstan TC, Chaplin EJ, et al. Bedside assessment of quadriceps muscle by ultrasound after admission for acute exacerbations of chronic respiratory disease. Am J Respir Crit Care Med. 2015;192(7):810-816.

72. Gifford JR, Trinity JD, Layec G, et al. Quadriceps exercise intolerance in patients with chronic obstructive pulmonary disease: the potential role of altered skeletal muscle mitochondrial respiration. J Appl Physiol. 2015;119(8):882-888.

73. Maltais F, Decramer M, Casaburi R, et al. An official American Thoracic Society/European Respiratory Society statement: update on limb muscle dysfunction in chronic obstructive pulmonary disease. Am J Respir Crit Care Med. 2014;189(9):e15-e62.

74. Iqbal J, Denvir M, Gunn J. Frailty assessment in elderly people. Lancet. 2013;381(9882):1985-1986.

75. Fried LP, Tangen CM, Walston J, et al. Frailty in older adults: evidence for a phenotype. J Gerontol A Biol Sci Med Sci. 2001;56(3): M146-M157.

76. Buta BJ, Walston JD, Godino JG, et al. Frailty assessment instruments: Systematic characterization of the uses and contexts of highly-cited instruments. Ageing Res Rev. 2016;26:53-61.

77. Fried LP, Borhani NO, Enright P, et al. The cardiovascular health study: Design and rationale. Ann Epidemiol. 1991;1(3):263-276.

78. Sourial N, Wolfson C, Bergman H, et al. A correspondence analysis revealed frailty deficits aggregate and are multidimensional. J Clin Epidemiol. 2010;63(6):647-654.

79. Baldwin MR, Singer JP, Huang D, et al. Refining low physical activity measurement improves frailty assessment in advanced lung disease and survivors of critical illness. Ann Am Thorac Soc. 2017;14(8):1270-1279.

80. Althoff KN, Jacobson LP, Cranston RD, et al. Age, comorbidities, and AIDS predict a frailty phenotype in men who have sex with men. J Gerontol A Biol Sci Med Sci. 2014;69(2):189-198.

81. Akgün KM, Tate JP, Oursler KK, et al. Association of chronic obstructive pulmonary disease with frailty measurements in HIV-infected and uninfected Veterans. AIDS. 2016;30(14):2185-2193. 
82. Morley JE, Malmstrom TK, Miller DK. A simple frailty questionnaire (FRAIL) predicts outcomes in middle aged African Americans. J Nutr Health Aging. 2012;16(7):601-608.

83. Woo J, Leung J, Morley JE. Comparison of frailty indicators based on clinical phenotype and the multiple deficit approach in predicting mortality and physical limitation. J Am Geriatr Soc. 2012;60(8):1478-1486.

84. Malmstrom TK, Miller DK, Morley JE. A Comparison of four frailty models. J Am Geriatr Soc. 2014;62(4):721-726.

85. Li Y, Zou Y, Wang S, et al. A pilot study of the FRAIL scale on predicting outcomes in Chinese elderly people with type 2 diabetes. J Am Med Dir Assoc. 2015;16(8):714.e7-714.e12.

86. Limpawattana P, Putraveephong S, Inthasuwan P, Boonsawat W, Theerakulpisut D, Chindaprasirt J. Frailty syndrome in ambulatory patients with COPD. Int J Chron Obstruct Pulmon Dis. 2017;12:1193-1198.

87. Rockwood K, Mitnitski A. Frailty in relation to the accumulation of deficits. J Gerontol A Biol Sci Med Sci. 2007;62(7):722-727.

88. Rockwood K, Song X, MacKnight C, et al. A global clinical measure of fitness and frailty in elderly people. Can Med Assoc J. 2005; 173(5):489-495.

89. Dent E, Chapman I, Howell S, Piantadosi C, Visvanathan R. Frailty and functional decline indices predict poor outcomes in hospitalised older people. Age Ageing. 2014;43(4):477-484.

90. Satake $\mathrm{S}$, Arai H. Implications of frailty screening in clinical practice. Curr Opin Clin Nutr Metab Care. 2017;20(1):4-10.

91. Hubbard RE, O'Mahony MS, Woodhouse KW. Characterising frailty in the clinical setting - a comparison of different approaches. Age Ageing. 2009;38(1):115-119.

92. Gale NS, Albarrati AM, Munnery MM, et al. Frailty: A global measure of the multisystem impact of COPD. Chron Respir Dis. 2018: 147997231775276.

93. Fukutomi E, Okumiya K, Wada T, et al. Relationships between each category of 25-item frailty risk assessment (Kihon Checklist) and newly certified older adults under Long-Term Care Insurance: a 24-month follow-up study in a rural community in Japan. Geriatr Gerontol Int. 2015;15(7):864-871.

94. Satake S, Senda K, Hong Y-J, et al. Validity of the Kihon Checklist for assessing frailty status. Geriatr Gerontol Int. 2016;16(6):709-715.

95. Satake S, Shimokata H, Senda K, Kondo I, Toba K. Validity of total Kihon checklist score for predicting the incidence of 3-year dependency and mortality in a community-dwelling older population. J Am Med Dir Assoc. 2017;18552(6):e551-e552.

96. Kusunose M, Oga T, Nakamura S, Hasegawa Y, Nishimura K. Frailty and patient-reported outcomes in subjects with chronic obstructive pulmonary disease: are they independent entities? BMJ Open Respir Res 2017;4(1):e000196.

97. Rolfson DB, Majumdar SR, Tsuyuki RT, Tahir A, Rockwood K. Validity and reliability of the Edmonton Frail Scale. Age Ageing. 2006;35(5):526-529.

98. Hilmer SN, Perera V, Mitchell S, et al. The assessment of frailty in older people in acute care. Australas J Ageing. 2009;28(4):182-188.

99. Bernabeu-Mora R, García-Guillamón G, Valera-Novella E, GiménezGiménez LM, Escolar-Reina P, Medina-Mirapeix F. Frailty is a predictive factor of readmission within 90 days of hospitalization for acute exacerbations of chronic obstructive pulmonary disease: a longitudinal study. Ther Adv Respir Dis. 2017;11(10):383-392.

100. Lachs MS, Feinstein AR, Cooney LM, et al. A simple procedure for general screening for functional disability in elderly patients. Ann Intern Med. 1990;112(9):699-706.

101. Cacciatore F, Abete P, Mazzella F, et al. Frailty predicts long-term mortality in elderly subjects with chronic heart failure. Eur J Clin Invest. 2005;35(12):723-730.

102. Galizia G, Cacciatore F, Testa G, et al. Role of clinical frailty on longterm mortality of elderly subjects with and without chronic obstructive pulmonary disease. Aging Clin Exp Res. 2011;23(2):118-125.

103. Gobbens RJ, van Assen MA. The prediction of quality of life by physical, psychological and social components of frailty in communitydwelling older people. Qual Life Res. 2014;23(8):2289-2300.
104. Gobbens RJ, van Assen MA, Luijkx KG, Wijnen-Sponselee MT, Schols JM. The Tilburg Frailty Indicator: psychometric properties. J Am Med Dir Assoc. 2010;11(5):344-355.

105. Gobbens RJ, Schols JM, van Assen MA. Exploring the efficiency of the Tilburg Frailty Indicator: a review. Clin Interv Aging. 2017; 12:1739-1752.

106. Franssen FM, Broekhuizen R, Janssen PP, Wouters EF, Schols AM. Effects of whole-body exercise training on body composition and functional capacity in normal-weight patients with COPD. Chest. 2004;125(6):2021-2028.

107. Puhan MA, Gimeno-Santos E, Cates CJ, Troosters T. Pulmonary rehabilitation following exacerbations of chronic obstructive pulmonary disease. Cochrane Database Syst Rev. 2016;12:CD005305.

108. Latham NK, Harris BA, Bean JF, et al. Effect of a home-based exercise program on functional recovery following rehabilitation after hip fracture: a randomized clinical trial. JAMA. 2014;311(7):700-708.

109. Abizanda P, López MD, García VP, et al. Effects of an oral nutritional supplementation plus physical exercise intervention on the Physical function, nutritional status, and quality of life in frail institutionalized older adults: the ACTIVNES study. $J$ Am Med Dir Assoc. 2015;16(5):439.e9-439.e16.

110. Fragala MS, Dam TT, Barber V, et al. Strength and function response to clinical interventions of older women categorized by weakness and low lean mass using classifications from the Foundation for the National Institute of Health sarcopenia project. J Gerontol A Biol Sci Med Sci. 2015;70(2):202-209.

111. Ferreira IM, Brooks D, Lacasse Y, Goldstein RS. Nutritional supplementation in stable chronic obstructive pulmonary disease. Cochrane Database Syst Rev. 2000;3(3):CD000998.

112. Payette H, Boutier V, Coulombe C, Gray-Donald K. Benefits of nutritional supplementation in free-living, frail, undernourished elderly people: a prospective randomized community trial. J Am Diet Assoc. 2002;102(8):1088-1095.

113. Walston J, Buta B, Xue QL. Frailty screening and interventions: considerations for clinical practice. Clin Geriatr Med. 2018;34(1): 25-38.

114. Omidvari AH, Vali Y, Murray SM, Wonderling D, Rashidian A. Nutritional screening for improving professional practice for patient outcomes in hospital and primary care settings. Cochrane Database Syst Rev. 2013;6(6):CD005539.

115. Onder G, Penninx BW, Balkrishnan R, et al. Relation between use of angiotensin-converting enzyme inhibitors and muscle strength and physical function in older women: an observational study. Lancet. 2002;359(9310):926-930.

116. Bibas L, Levi M, Bendayan M, Mullie L, Forman DE, Afilalo J. Therapeutic interventions for frail elderly patients: part I. Published randomized trials. Prog Cardiovasc Dis. 2014;57(2):134-143.

117. Bauer JM, Verlaan S, Bautmans I, et al. Effects of a vitamin D and leucine-enriched whey protein nutritional supplement on measures of sarcopenia in older adults, the PROVIDE study: a randomized, double-blind, placebo-controlled trial. J Am Med Dir Assoc. 2015; 16(9):740-747.

118. Beswick AD, Rees K, Dieppe P, et al. Complex interventions to improve physical function and maintain independent living in elderly people: a systematic review and meta-analysis. Lancet. 2008; 371(9614):725-735.

119. Ellis G, Gardner M, Tsiachristas A, et al. Comprehensive geriatric assessment for older adults admitted to hospital. Cochrane Database Syst Rev. 2017;9:CD006211

120. Acosta-Benito MA, Sevilla-Machuca I. Using prefrailty to detect early disability. J Family Community Med. 2016;23(3):140-144.

121. Valenza MC, Torres-Sánchez I, Cabrera-Martos I, Rodríguez-Torres J, González-Jiménez E, Muñoz-Casaubon T. Physical activity as a predictor of absence of frailty in subjects with stable COPD and COPD exacerbation. Respir Care. 2016;61(2):212-219. 


\section{Publish your work in this journal}

Clinical Interventions in Aging is an international, peer-reviewed journal focusing on evidence-based reports on the value or lack thereof of treatments intended to prevent or delay the onset of maladaptive correlates of aging in human beings. This journal is indexed on PubMed Central, MedLine,

CAS, Scopus and the Elsevier Bibliographic databases. The manuscript management system is completely online and includes a very quick and fair peer-review system, which is all easy to use. Visit http://www.dovepress. com/testimonials.php to read real quotes from published authors. 